\title{
Saint-Dizier-Leyrenne - Murat « Les Tours »
}

$n^{\circ} 3270$

\section{Philippe Racinet et Richard Jonvel}

\section{(2) OpenEdition \\ 12 Journals}

Édition électronique

URL : http://journals.openedition.org/adlfi/16170

ISSN : 2114-0502

Éditeur

Ministère de la culture

Référence électronique

Philippe Racinet et Richard Jonvel, « Saint-Dizier-Leyrenne - Murat « Les Tours » », ADLFI. Archéologie de la France - Informations [En ligne], Limousin, mis en ligne le 18 janvier 2016, consulté le 01 mai 2019. URL : http://journals.openedition.org/adlfi/16170

Ce document a été généré automatiquement le 1 mai 2019.

(c) Ministère de la Culture et de la Communication, CNRS 


\title{
Saint-Dizier-Leyrenne - Murat « Les Tours »
}

$\mathrm{n}^{\circ} 3270$

\author{
Philippe Racinet et Richard Jonvel
}

Code Insee commune : 23189

Lien Atlas (MCC) :

http://atlas.patrimoines.culture.fr/atlas/trunk/index.php?

ap_theme=DOM_2.01.02\&ap_bbox=1.645;45.988;1.785;46.070

1 Le plan topographique, réalisé en 2012, indiquait nettement les aménagements anthropiques de ce petit éperon barré, ce qui a motivé l'intervention de 2013. Afin de ne pas miter le site, un seul sondage, d'une largeur de 1,50 $\mathrm{m}$ et dans l'axe du promontoire, a pris en compte la plate-forme de la butte (sur 9,50 m de long), le talus de rebord, l'escarpe, le fond du fossé et le talus de contrescarpe (fig. 1).

2 Le talus de rebord correspond à une muraille composée de pierres stabilisées par la technique de la vitrification. Au moment de sa mise en œuvre, le rempart était constitué d'armatures en bois qui maintenaient les pierres. Le feu était mis à cette structure ce qui avait pour conséquence, du fait de l'élévation de température, d'entraîner la fusion des pierres avec les armatures et de donner lieu à la vitrification de l'ensemble. Cette technique consolide durablement la muraille, mais il faut établir une surface plane et lisse à la base, ce qui nécessite un défrichement et un taillage de la roche.

3 Sur la plate-forme protégée par la muraille précédente (fig. 2), une couche de charbon de bois repose directement sur le rocher taillé ; on y trouve des traces de poutres calcinées contenant des éléments métalliques. Sous cette couche, le rocher est percé de trois trous de poteau, principaux aménagements anthropiques retrouvés à ce stade de l'enquête.

Un fossé creusé dans le rocher a été parfaitement déterminé du côté de la pointe de l'éperon (fig. 3). La roche taillée devait apparaître directement lors de l'utilisation du fossé, si l'on en croit son aspect très délité. Ce fossé, d'une emprise de 10,70 m, est composé d'une partie haute en léger creux au pied de l'escarpe (emprise de 2,40 m), 
renforçant ainsi son caractère abrupt (hauteur totale entre le haut du talus et le fond du fossé : 6,20 m), et d'une partie basse en pente douce vers la contrescarpe (emprise de $3,45 \mathrm{~m}$ ), où la roche est taillée verticalement sur $0,35 \mathrm{~m}$. Le comblement est homogène.

5 L'ensemble du sondage n'a fourni qu'un mobilier résiduel, peu datant, notamment 9 éléments métalliques dans la couche charbonneuse (essentiellement de gros clous). Il a donc été procédé à une datation par radiocarbone de la couche de charbon de bois : intervalle calibré : 718-892 apr.J.-C. La couche ainsi datée est interprétée comme une conséquence directe de la vitrification du rempart; le résultat obtenu renvoie donc à l'époque de la mise en place de ce système défensif.

6 Ainsi, Murat serait un site castral d'époque carolingienne, mentionné à plusieurs reprises dans les actes comtaux du XIII ${ }^{e}$ s. comme prévôté, au même titre que Crozant ou les autres châtellenies comtales. Rapidement déclassé et rattaché à la prévôté voisine du Dognon, pour des raisons de gestion administrative, il ferait partie de cette génération de castra d'origine mal établie dont les comtes de la Marche ont cherché à s'assurer le contrôle, et réussi.

Fig. 1

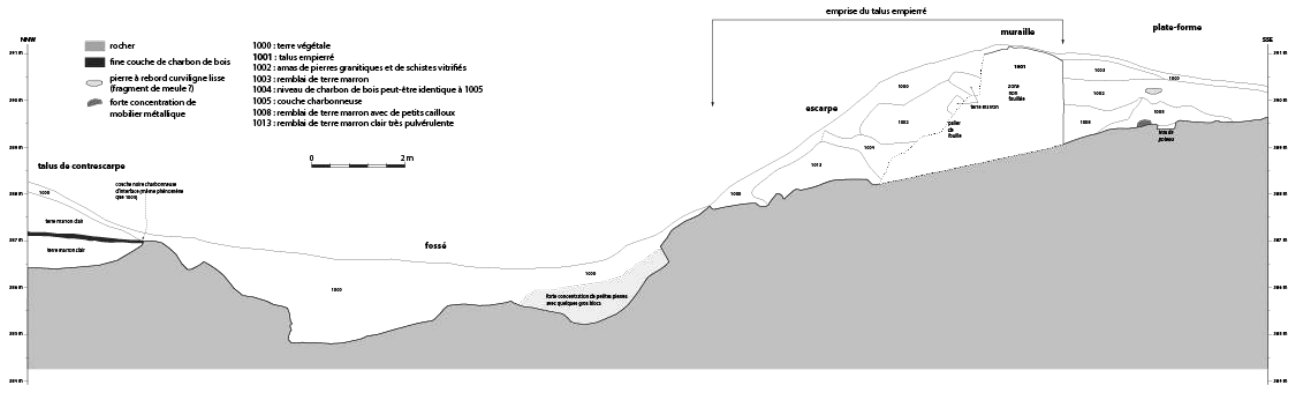

Stratigraphie nord-nord-ouest/sud-sud-est du sondage de 2013.

Dessin : P. Augé, DAO : Ph. Racinet, Université de Picardie 
Fig. 2

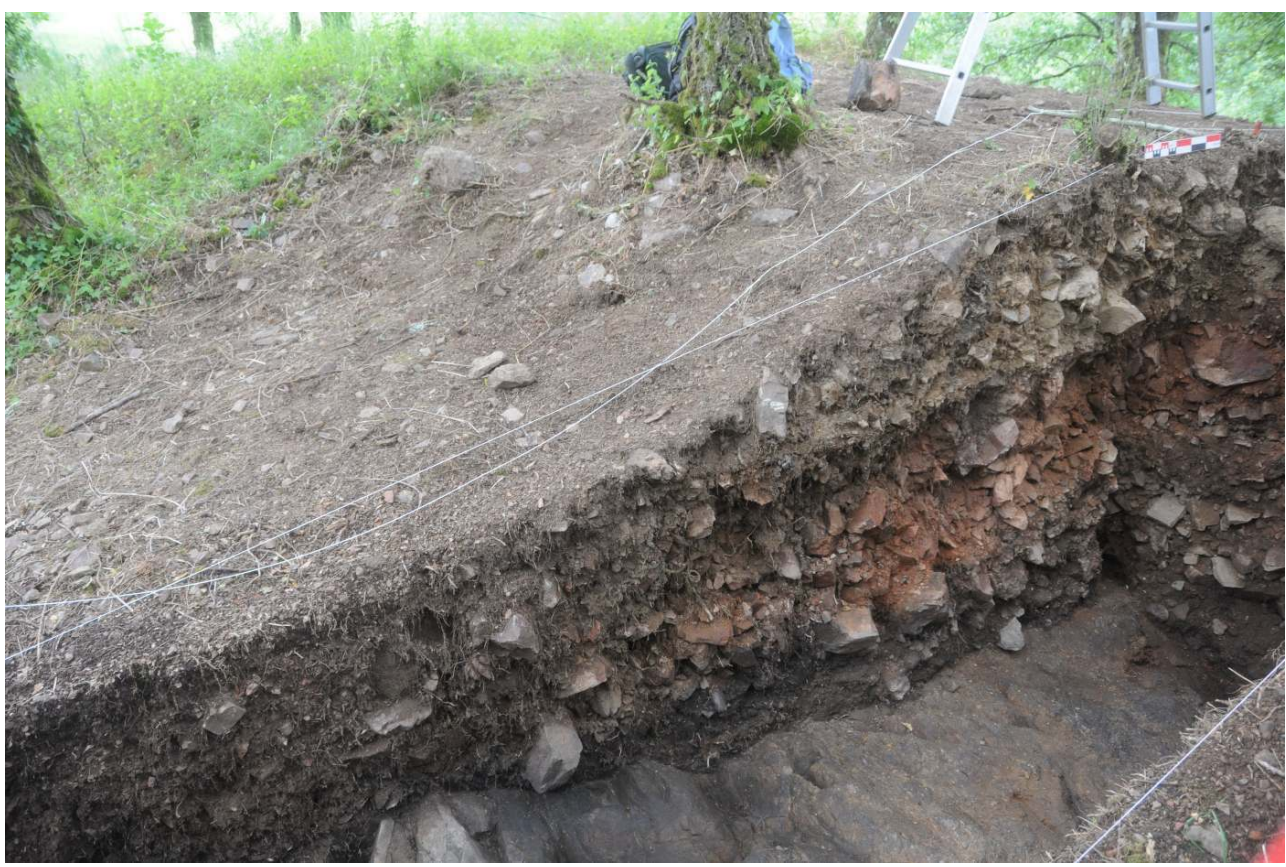

Berme occidentale du sondage au niveau de la plate-forme.

Cliché : R. Jonvel, Université de Picardie

Fig. 3

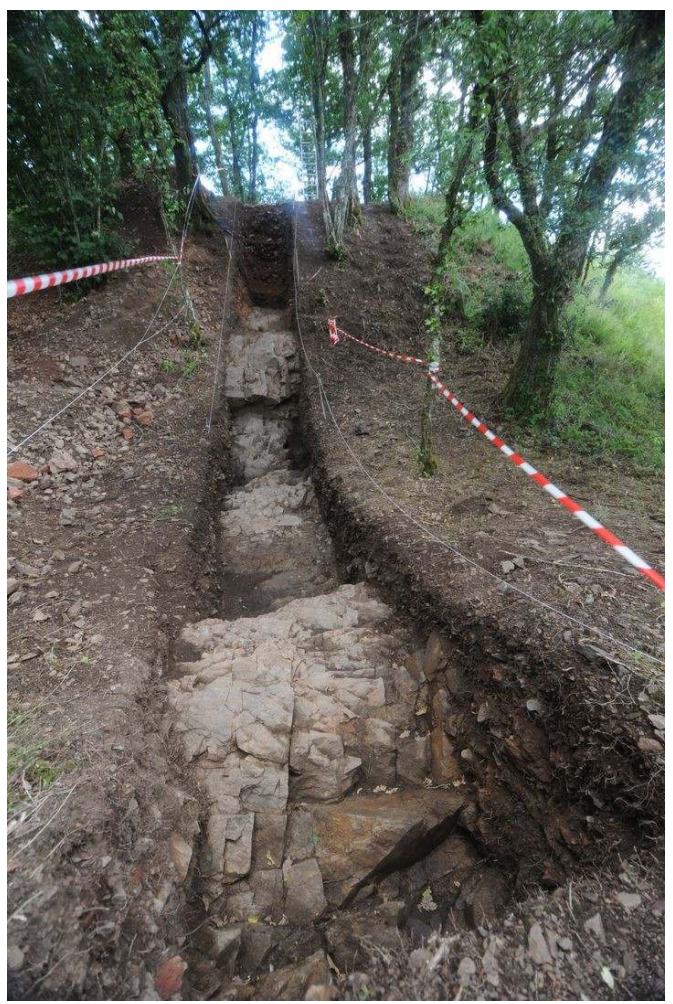

Fossé vu du talus de contrescarpe.

Cliché : R. Jonvel, Université de Picardie 
INDEX

Index géographique : Limousin, Creuse (23), Saint-Dizier-Leyrenne

Keywords : Early Middle Ages, fortification

Index chronologique : haut Moyen Âge

operation Sondage (SD)

Mots-clés : fortification

AUTEURS

PHILIPPE RACINET

SUP 